\title{
Comparing the Immunoexpression of FUT3 and FUT6 between Prostatic Adenocarcinoma and Benign Prostatic Hyperplasia
}

\author{
Juliana Lúcia de Albuquerque Vasconcelos ${ }^{1}$, Steffany de Almeida Ferreira ${ }^{1}$, \\ Amanda Lucena Rosendo de Lima ${ }^{1}$, Moacyr Jesus Barreto de Melo Rêgo', \\ Ana Rosa Galdino Bandeira ${ }^{1}$, Carmelita de Lima Bezerra Cavalcanti', \\ Mariana Montenegro de Melo Lira² ${ }^{2}$ and Eduardo Isidoro Carneiro Beltrão ${ }^{1,3}$
}

\begin{abstract}
${ }^{1}$ Laboratório de Imunopatologia Keizo Asami (LIKA), Universidade Federal de Pernambuco (UFPE), Av. Prof. Moraes Rêgo, s/n CDU, Recife, PE, Brazil 50670-901, 2Departamento de Patologia, Universidade Federal de Pernambuco (UFPE), Av. Prof. Moraes Rêgo, s/n CDU, Recife, PE, Brazil 50670-901 and ${ }^{3}$ Departamento de Bioquímica, Universidade Federal de Pernambuco (UFPE), Av. Prof. Moraes Rêgo, s/n CDU, Recife, PE, Brazil 50670-901
\end{abstract}

Received March 18, 2013; accepted May 2, 2013; published online June 20, 2013

\begin{abstract}
Prostatic Adenocarcinoma (PA) and Benign Prostatic Hyperplasia (BPH) have their etiology not fully understood mainly in glycidic aspects. Glycan changes are associated with cell alterations where glycosylation is carried out by glycosyltransferases, such as fucosyltransferases (FUTs). These enzymes catalyze the insertion of L-fucose residues in a variety of glycan structures often in the final stage of glycosylation. The present study aimed to investigate the expression of FUT3 and FUT6 in PA and BPH as well as to correlate immunostaining of these transferases with PA clinic-histopathologic data. The FUT3 and FUT6 expressions were evaluated by immunohistochemistry in formalin-fixed, paraffinembedded biopsies of PA $(n=40)$ and BPH $(n=40)$. FUT3 and FUT6 showed a high expression in both prostatic diseases, especially FUT6. FUT6 was more immunoexpressed in PA cases than the FUT3 $(p<0.0001)$ as well as in BPH cases but in a not significant way $(p=0.0661)$. Besides, FUT3 was more expressed in BHP lesion than in PA cases $(p<0.0001)$. Our study presented a new data about FUT3 and FUT6 expression in PA and BPH, revealing high FUT6 expression in both lesions and FUT3 overexpression in BHP in relation to PA, proposing that this enzyme could be a promising biomarker for benign prostate alterations.
\end{abstract}

Key words: fucosyltransferases, L-fucose, prostatic adenocarcinoma, benign prostatic hyperplasia

\section{Introduction}

Prostatic Adenocarcinoma (PA) is the second most frequent cause of cancer death among men from western countries [12] but its etiology is not fully understood. Benign prostatic hyperplasia (BPH) has the highest preva-

Correspondence to: Juliana Lúcia de Albuquerque Vasconcelos, Universidade Federal de Pernambuco (UFPE), Av. Prof. Moraes Rêgo, s/n CDU, Recife, PE, Brazil 50670-901.

E-mail: juli6296@yahoo.com.br lence among prostate diseases and, beside this, its etiology is also poorly understood [6]. Both diseases are usually associated with genetics, metabolic [5], proteomics [22] and glycomic alterations [28].

Glycomics assess functional and structural properties of glycoconjugates and their changes in many diseases through the glycosylation mechanism [26]. This biochemistry process is conducted by various glycosyltransferases being one of the most versatile and abundant coand post-translational modifications of proteins and lipids [15]. One key glycosylation type is fucosylation, mainly 
during embryogenesis, development, cell adhesion, apoptosis and also in diseases [4, 15]. This process is mediated by fucosyltransferases (FUTs), an enzyme family, which it is codified by fucosyltransferases genes [18], acting in a variety of glycans with biological importance, often, in the final stage of glycosylation $[8,18]$. These enzymes catalyze the transfer of the L-fucose residues from GDP-L-fucose (GDP-Fuc) metabolites to various acceptors via an $\alpha 1,2-$, $\alpha 1,3-, \alpha 1,4-\mathrm{e} \alpha 1,6-$ linkage $[13,30]$. Nine FUTs have been identified so far and among them six catalyze $\alpha 1,3$ linkage; they are FUTs 3, 4, 5, 6, 7 and 9 [29, 30]. FUT3 and FUT6 are involved in the synthesis of sialyl Lewis $\mathrm{X}\left(\mathrm{sLe}^{\mathrm{x}}\right)$ structure [NeuAc $\alpha 2-3 \mathrm{Gal} \beta 1-4$ (Fuc $\alpha 1-3)$ GlcNAc $\beta-\mathrm{R}$ ], and Le $^{\mathrm{x}}$ structure, [Gal $\beta 1-4($ Fuc $\alpha 1-3)$ GlcNAc $\left.\beta-R\right]$ and FUT3 can also exhibit $\alpha 1-4$ fucosyltransferase activity, resulting in the synthesis of type 1 Lewis antigens such as Le ${ }^{\mathrm{a}}$ [Gal $\beta 1-3$ (Fuc $\alpha 1-4)$ GlcNAc $\beta-R]$ and Le ${ }^{\mathrm{b}}$ [(Fuc $\left.\alpha 1-2\right)$ Gal $\beta 1-$ 3(Fuc $\alpha 1-4)$ GlcNAc $\beta$ [29].

Many studies have been demonstrating the involvement of FUTs in cancer progression [3, 7, 8, 16, 20], being found over-expressed during tumorigenesis and neoplastic progression in thyroid carcinoma, ovarian carcinoma, colorectal adenocarcinoma, breast cancer and brain metastasis from lung carcinoma [31]. In metastatic prostate cancer it is also observed their activity forming Lewis antigens, facilitating interaction with E-selectin in the vascular endothelium, via L-fucose residues [3]. In the present study, we investigated the FUT3 and FUT6 expression in PA and $\mathrm{BPH}$ and their correlation with PA clinical and histopatological data.

\section{Materials and Methods}

\section{Tissue samples}

Eighty formalin-fixed, paraffin-embedded PA $(\mathrm{n}=40)$ and BPH $(n=40)$ samples were obtained from patients who were diagnosed by two independent pathologists from Hospital das Clínicas, Universidade Federal de Pernambuco (HC-UFPE), Northeast of Brazil, between the years of 2007 and 2009. PA clinical and histopathological data including age, tumor aggressiveness, Gleason classification and pTNM classification were obtained at the Pathology sector of the same hospital. This project was approved by the Health Center Science Ethical Committee CCS-UFPE (SISNEP FR-272931, CEP/CCS/UFPE N 195/09).

\section{Immunohistochemistry (IHC)}

Four-micrometer tissue sections from formalin-fixed, paraffin-embedded biopsies were deparaffinized in xylene and hydrated in graded ethanol (70-100\%). Afterwards, samples were submitted to antigen retrieval in $10 \mathrm{mM}$ citrate buffer ( $\mathrm{pH}$ 6.0) in a vapor chamber for $30 \mathrm{~min}$; after cooling, the slices were incubated with hydrogen peroxidemethanol solution $(1: 1)$ for $30 \mathrm{~min}$ at $25^{\circ} \mathrm{C}$, followed by blocking with bovine serum albumin 1\% (BSA) solution (prepared in $100 \mathrm{mM}$ sodium phosphate buffer solution, $\mathrm{pH}$ 7.2-PBS) for $1 \mathrm{hr}$. Then, the slices were incubated with rabbit polyclonal antibody anti-FUT3 (1 : 200, SigmaAldrich, St. Louis, MO, USA) and polyclonal antibody anti-FUT6 (1 : 200, Sigma-Aldrich, St. Louis, MO, USA), separately, overnight at $4^{\circ} \mathrm{C}$. Incubation with ADVANCE ${ }^{\mathrm{TM}}$ HRP LINK (DAKO, Produktionsvej, Denmark) was performed for $45 \mathrm{~min}$, followed by ADVANCE ${ }^{\mathrm{TM}} \mathrm{HRP}$ ENZIME (Produktionsvej, Denmark) for $45 \mathrm{~min}$ both at $25^{\circ} \mathrm{C}$, a biotin-free polymer method. Peroxidase reaction was revealed with 3,3'-diaminobenzidine (DAKO, Produktionsvej, Denmark) and hematoxylin was used for counter-staining. Washes between protocol steps were performed with $10 \mathrm{mM}$ sodium phosphate buffer, containing $\mathrm{NaCl} 0.15 \mathrm{M}$ (PBS), pH 7.2 ( $2 \times 5$ min). Negative staining controls were obtained by replacing primary antibodies for PBS-BSA. For image acquisition, an Image Analyses System (software NIS - Elements F version 2.30 -Nikon, Tokyo, Japan) was used and the results were analyzed by nonparametric tests (Fisher's exact test) with a significance level of 95\% $(\mathrm{p}<0.05)$ using GraphPad Software (San Diego, CA, USA). Tissue staining was classified as positive or negative based on the intensity of antibody signal (negative, weak, moderate and strong) and percentage of stained cells according to The Human Protein Atlas [27]. For statistical analysis, samples were dichotomized in positive and negative groups, considering positive samples when more than $10 \%$ of neoplastic cells were moderate or strong reactive to FUTs antibodies.

\section{Results}

FUT3 and FUT6 immunoexpression in PA and BPH were observed in cytoplasm-perinuclear staining, consistent with the Golgi apparatus localization (Fig. 1). The staining intensity were homogeneous for both FUTs. FUT3 showed a weak to moderate staining pattern in both BPH and PC lesions. On the other hand, FUT6 showed moderate to intense staining pattern for both pathologies. FUT6 was more immunoexpressed in PA cases than FUT3 ( $>0.0001)$, staining thirty-eight samples (95\%) for FUT6 and seventeen samples (42.5\%) for FUT 3. In BPH lesions, FUT6 was more expressed than FUT3, thirty-seven samples $(92.5 \%)$ and thirty samples $(75 \%)$ respectively, despite this different expression pattern it was not statistically significant $(p=0.0661)$. Interestingly, FUT3 results revealed the overexpression of this enzyme in $\mathrm{BPH}$ in relation to PA $(\mathrm{p}=0.033)$, differing from FUT6 that is overexpressed in both lesions (Fig. 2).

FUT3 and FUT6 immunoexpression patterns and their correlation with clinic-histopathologic features in PA (age, tumor aggressiveness, Gleason classification, pT classification, $\mathrm{pN}$ classification and distant metastasis status) are presented (data not shown). It was not found any correlation between FUTs IHC and PA data.

\section{Discussion}

Carbohydrates in cell surface molecules, such as in 

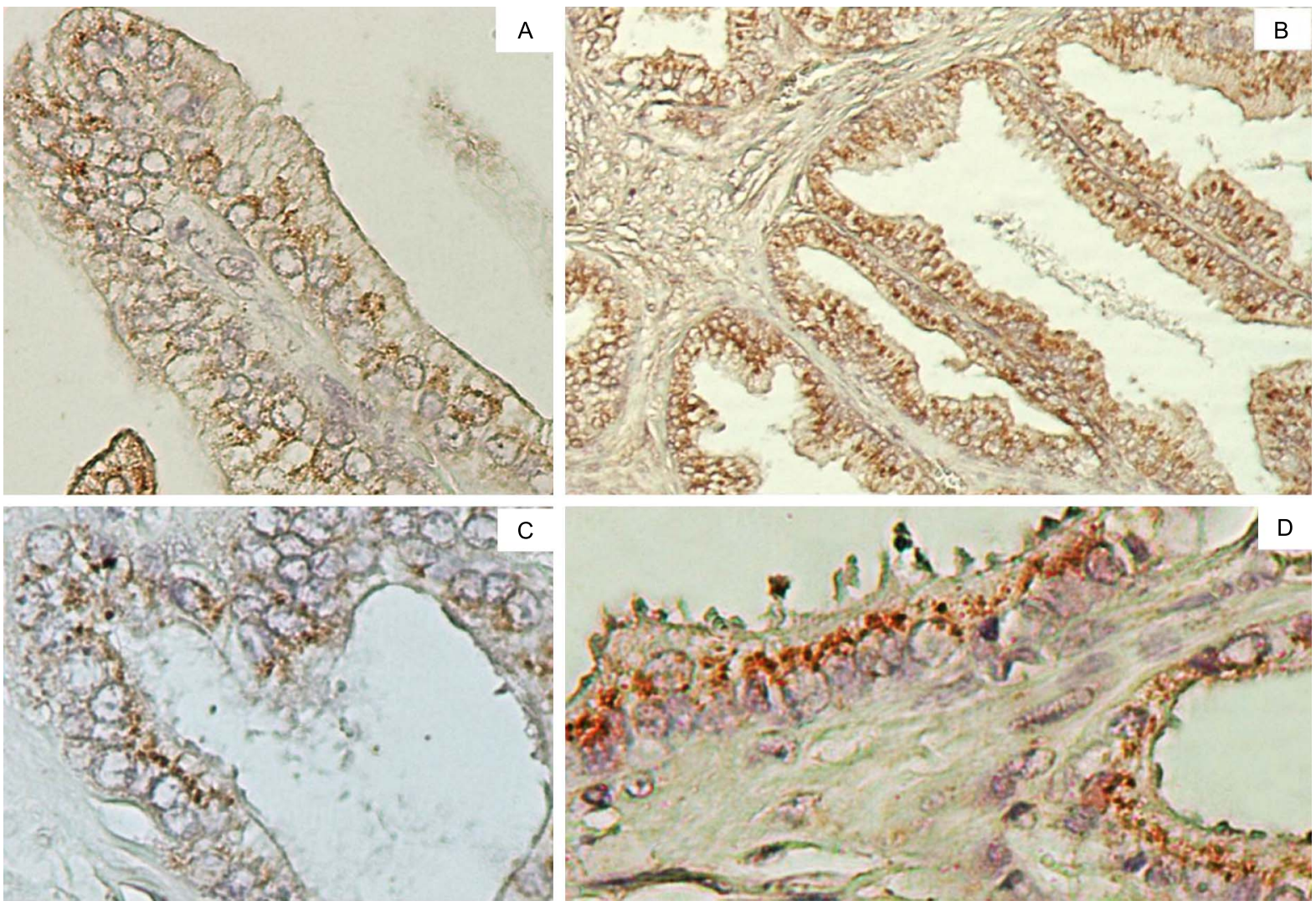

Fig. 1. FUT3 and FUT6 immunoexpression profile. A) and B) presents FUT3 and FUT6 stainings in BPH, respectively. C) and D) shows FUT3 and FUT6 staining pattern in PA, respectively. In all figures indicates perinuclear and granular staining typical from Golgi apparatus.

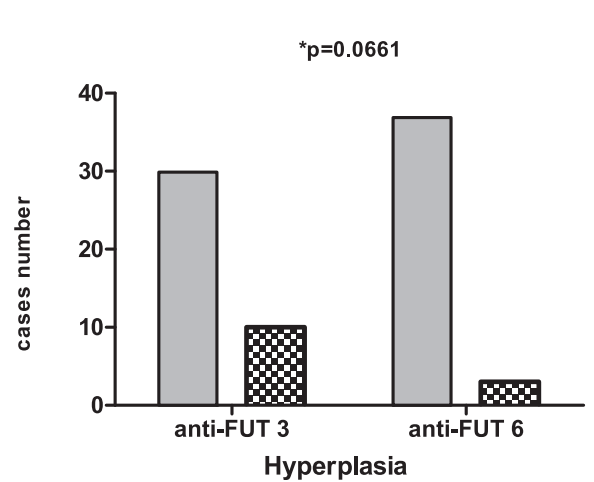

A

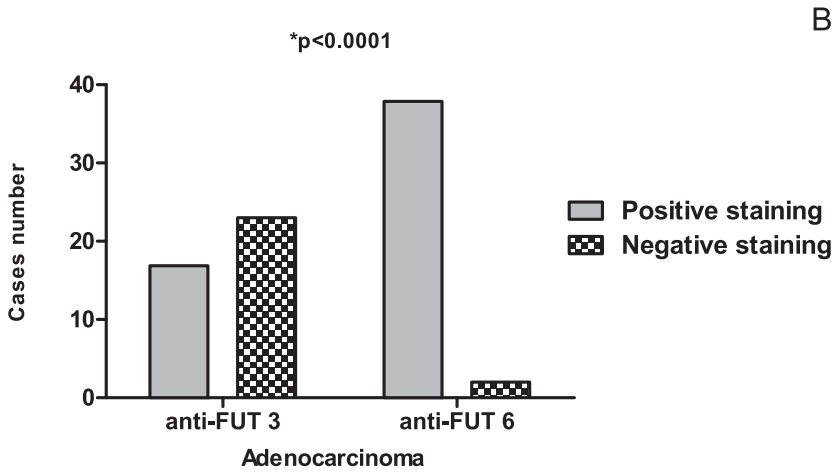

Fig. 2. Evaluation of FUTs in PA and BHP. A) FUT6 are more expressed in BHP cases than FUT3. B) FUT6 are more expressed in PA cases than FUT3. Comparing A and $\mathbf{B}$ can be observed FUT3 overexpression in BPH in relation to PA cases ( $p=0.033)$.

glycoconjugates, play important roles in neoplastic cells altering components in many different cancers, and it is known to be correlated with proliferation, invasiveness and metastasis [29]. Cell molecules are glycosylated by a series of glycosyltransferases resulting in glycan structures changes that may vary according to the physiological status of the organ [21]. FUTs are one type of these enzymes involved in glycosylation and their expressions have been studied in gastrointestinal carcinoma cell lines, gastric can- cer cell lines, colon cancer cell lines, colorectal carcinoma tumor; prostate cancer cell lines, and ovarian carcinoma tumors cell lines [3, 4, 7, 10, 14, 23, 29, 30]. Nearly, most of all malignant cells demonstrate alterations in their glycosylation patterns when compared to their normal counter-part. According to Ghazarian et al. [11], alterations in glycosylation are often the result of altered activities of their respective enzymes, as it is evident in the specific and preferential display of certain glycoconjugates on cancer 
cells. In our work, FUT3 and FUT6 expression was studied in PA and BPH. Stern et al. [25] is the only study regarding FUT3 and FUT6 expression using immunohistochemistry in lung and prostate normal tissue, showing no staining for both. On the other hand, normal colon and kidney tissues showed high immunoexpression for both enzymes as well as colorectal tumor, showing high immunoexpression for FUT3 and FUT6 in $70 \%$ of cases.

No data were found, so far, relating these enzymes immunostaining with PA and BPH tissue using IHC. The FUT6 overexpression in PA cases $(p>0.0001)$ and FUT3 and FUT6 in BPH cases (even with no statistic significance) observed by IHC are in accordance with Barthel and coworkers' results [3, 4]. By using molecular biology techniques, they showed that FUT3 and FUT6 overexpression in PA are involved with metastasis via Sialyl Lewis ${ }^{\mathrm{x}}$ synthesis induction, E-selectin-mediated adhesion induction and cell trafficking. Therefore, Yin et al. [30] observed that FUT3 is highly expressed in prostate cancer cell line MDA PCa2b, increasing cell growth rate and circulation if epithelial cancer cells. Our study showed the localization of these enzymes in cytoplasmic points, suggesting the Golgi apparatus, confirming that the glycosylation process is highly active and that these two enzymes are important for tumor features [25]. Thus, our research corroborates with studies using lectin histochemistry, specific for $\alpha 1-3$ and $\alpha 1-4$ L-fucose in PA $[1,2,9,19,24]$ and BPH tissues [2, 17], demonstrating for the first time the immunostaining of enzymes responsible for adding fucose residues in prostatic tissues.

In summary, this study showed new data about FUT3 and FUT6 expression in PA and BPH, especially for FUT6, proposing that these enzymes could be promising targets for prostate alterations. Besides this, it showed FUT3 overexpression in BHP in relation to PA, proposing that this enzyme could be a promising biomarker for benign prostate alterations. More studies are in progress to elucidate the role of FUT6 in the carcinogenesis and in the maintenance and development of prostatic tumors.

\section{Acknowledgments}

Authors thank Fundação de Amparo à Ciência e Tecnologia do Estado de Pernambuco (FACEPE) and Conselho Nacional de Desenvolvimento Científico e Tecnológico $(\mathrm{CNPq})$ for research grants.

\section{Declaration of Interest}

Authors have no conflict of interest that might harm the impartiality of this research.

\section{Disclosure Statement}

Authors have nothing to declare.

\section{References}

1. Abel, P. D., Keane, P., Leathem, A., Butt, S. T. and Williams, G. (1989) Change in Glycoconjugate for the binding site of the lectin Ulex europeus 1 following malignant transformation of prostatic epithelium. Br. J. Urol. 63; 183-185.

2. Arenas, M. I., Romo, E., Gaspar, I., Bethencourt, F. R., Chapada, M. S., Fraile, B. and Paniagua, R. (1999) A lectin histochemistry comparative study in human normal prostate, benign prostatic hyperplasia, and prostatic carcinoma Lectin histochemistry of the human prostate. Glycoconj. J. 16; 375-382.

3. Barthel, S. R., Gavino, J. D., Wiese, G. K., Jennifer, M. J., Javed, S. and Charles, J. D. (2008) Analysis of glycosyltransferase expression in metastatic prostate cancer cells capable of rolling activity on microvascular endothelial (E)-selectin. Glycobiology $18 ; 806-817$.

4. Barthel, S. R., Wiese, G. K., Cho, J., Opperman, M. J., Hays, D. L., Siddiqui, J., Pienta, K. J., Furie, B. and Dimitroff, C. J. (2009) Alpha 1,3fucosyltransferases are master regulators of prostate cancer cell trafficking. Proc. Natl. Acad. Sci. U S A 106; 1949119496.

5. Benedettini, E., Nguyen, P. and Loda, M. (2008) The pathogenesis of prostate cancer: from molecular to metabolic alterations. Diagn. Histopathol. (Oxf). 14; 195-201.

6. Brum, I. S., Spritzer, P. M. and Brentani, M. M. (2005) Biologia Molecular das Neoplasias de Próstata. Arq. Bras. Endocrinol. Metab. 49; 797-804.

7. Carvalho, A. S., Harduin-Lepers, A., Magalhães, A., Machado, E., Mendes, N., Costa, L. T., Matthiesen, R., Almeida, R., Costa, J. and Reis, C. A. (2010) Differential expression of alpha2,3sialyltransferases and alpha1,3/4-fucosyltransferases regulates the levels of sialyl Lewis a and sialyl Lewis $\mathrm{x}$ in gastrointestinal carcinoma cells. Int. J. Biochem. Cell Biol. 42; 80-89.

8. Chang, W. W., Lee, C. H., Lee, P., Lin, J., Hsu, C. W., Hung, J. T., Lin, J. J., Yu, J. C., Shao, L. E., Yu, J., Wong, C. H. and Yu, A. L. (2008) Expression of Globo H and SSEA3 in breast cancer stem cells and the involvement of fucosyltransferases 1 and 2 in Globo H synthesis. Proc. Natl. Acad. Sci. U S A 105; 11667-11672.

9. Drachenberg, C. B. and John, J. C. (1995) Aberrant pattern of lectin binding in low and high grade prostatic Intraepithelial neoplasia. Cancer 75; 2539-2544

10. Escrevente, C., Machado, E., Brito, C., Reis, C. A., Stoeck, A., Runz, S., Marme, A., Altevogt, P. and Costa, J. (2006) Different expression levels of $\alpha 3 / 4$ fucosyltransferases and Lewis determinants in ovarian carcinoma tissues and cell lines. Int. J. Oncol. 29; 557-566.

11. Ghazarian, H., Idoni, B. and Oppenheimer, S. B. (2011) A glycobiology review: Carbohydrates, lectins and implications in cancer therapeutics. Acta Histochem. 113; 236-247.

12. Jankovic, M. M. and Kosanovic, M. M. (2008) Fibronectin pattern in benign hyperplasia and cancer of the prostate. Dis. Markers 25; 49-58.

13. Javaudi, C., Dupuy, F., Maftah, A., Julien, R. and Petit, J. M. (2003) The fucosyltransferase gene family: an amazing summary of the underlying mechanisms of gene evolution. Genetica 118; $157-170$.

14. Li, W., Zhang, W., Luo, J., Cao, A., Zhang, Y., Huang, D., Sheng, W., Cai, S. and Li, J. (2010) Alpha1,3 fucosyltransferase VII plays a role in colorectal carcinoma metastases by promoting the carbohydration of glycoprotein CD24. Oncol. Rep. 23; 16091617.

15. Maeda, T. and Nishimura, S. I. (2008) FRET-based direct and continuous monitoring of human fucosyltransferases activity: an efficient synthesis of versatile GDP-L-fucose derivatives from abundant D-galactose. Chem. Eur. J. 14; 478-487.

16. Marker, P. C., Stephan, J. P., Lee, J., Bald, L., Mather, J. P. and Cunha, G. R. (2001) Fucosyltransferase1 and H-type complex 
carbohydrates modulate epithelial cell proliferation during prostatic branching morphogenesis. Dev. Biol. 233; 95-108.

17. Morales, E., Polo, L. A., Pastor, L. M., Santamar, L., Calvo, A., Zuasti, A. and Ferrer, C. (2005) Characterization of corpora amylacea glycoconjugates in normal and hyperplastic glands of human prostate. J. Mol. Histol. 36; 235-242.

18. Moriwaki, K. and Miyoshi, E. (2010) Fucosylation and gastrointestinal cancer. World J. Hepatol. 2; 151-161

19. Pacis, R., Pilat, M., Yamazaki, K. and Pienta, K. (1995) Differential carbohydrate expression in tumorigenic vs nontumorigenic prostate cell-lines. Int. J. Oncol. 7; 1349-1354.

20. Potapenko, I. O., Hakensen, V. D., Luders, T., Helland, A., Bukholm, I., Sørlie, T., Kristensen, V. N., Lingjaerde, O. C. and Børresen-Dale, A. L. (2010) Glycan gene expression signitures in normal and malignant breast tissue; possible role in diagnosis and progression. Mol. Oncol. 4; 98-118.

21. Rosenfeld, R., Bangio, H., Gerwig, G. J., Rosenberg, R., Aloni, R., Cohen, Y., Amor, Y., Plaschkes, I., Kamerling, J. P. and Maya, R. B. (2007) A lectin array-based methodology for the analysis of protein glycosylation. J. Biochem. Biophys. Methods 70; 415426.

22. Schwamborn, K., Krieg, R. C., Reska, M., Jakse, G., Knuechel, R. and Wellmann, A. (2007) Identifying prostate carcinoma by MALDI-Imaging. Int. J. Mol. Med. 20; 155-159.

23. Serpa, J., Mesquita, P., Mendes, N., Oliveira, C., Almeida, R., Silva, F. S., Reis, C. A., LePendu, J. and David, L. (2006) Expression of Lea in gastric cancer cell lines depends on FUT3 expression regulated by promoter methylation. Cancer Lett. 242; 191-197.

24. Soderstrom, K. O. (1987) Lectin binding to prostatic adenocarcinoma. Cancer 60; 1823-1831.

25. Stern, H. M., Padilha, M. and Wagner, K. (2010) Development of immunohistochemistry assays to assess GALNT14 and FUT3/6 in clinical trials of dulanermin and drozitumab. Clin. Cancer Res. $16 ; 1587-1596$

26. Turnbull, J. E. and Field, R. A. (2007) Emerging glycomics technologies. Nat. Chem. Biol. 3; 74-77.

27. Uhlen, M., Oksvold, P., Fagerberg, L., Lundberg, E., Jonasson, K., Forsberg, M., Zwahlen, M., Kampf, C., Wester, K., Hober, S., Wernerus, H., Björling, L. and Ponten, F. (2010) Towards a knowledge-based human protein atlas. Nat. Biotechnol. 28; $1248-1250$

28. White, K. Y., Rodemich, L., Nyalwidhe, J. O., Comunale, M. A., Clements, M. A., Lance, R. S., Schellhammer, P. F., Mehta, A., Semmes, O. J. and Drake, R. R. (2009) Glycomic characterization of prostate specific antigen and prostatic acid phosphatase in prostate cancer and benign disease seminal plasma fluids. $J$. Proteome Res. 8; 620-630.

29. Yang, X., Zhang, Z., Jia, S., Liu, Y., Wang, X. and Yan, Q. (2007) Overexpression of fucosyltransferase IV in A431 cell line increases cell proliferation. Int. J. Biochem. Cell Bio. 39; 17221730.

30. Yin, X., Kuldeepsinh, R., Ponmudi, V. and King, M. R. (2010) Knockdown of fucosyltransferase III disrupts the adhesion of circulating cancer cells to E-selectin without affecting hematopoietic cell adhesion. Carbohydr. Res. 345; 2334-2342.

31. Yuan, K., Listinsky, C. M., Singh, R. K., Listinsky, J. J. and Siegal, G. P. (2008) Cell surface associated alpha-L-fucose moieties modulate human breast cancer neoplastic progression. Pathol. Oncol. 14; 145-156.

This is an open access article distributed under the Creative Commons Attribution License, which permits unrestricted use, distribution, and reproduction in any medium, provided the original work is properly cited. 